\title{
Knowledge, Attitude and Practice of Rabies in and Around Lafia Metropolis, Nigeria
}

\author{
Reuben Christopher Rine ${ }^{1, ~ *, ~ G y a r ~ S i l a s ~ D o g a r a ~}{ }^{1}$, Mwanta Dachung Pam² \\ ${ }^{1}$ Department of Science Laboratory Technology (Microbiology/Biology Unit), Nasarawa State Polytechnic, Lafia, Nigeria \\ ${ }^{2}$ Environmental Health Department, College of Health Technology, Zawan, Nigeria
}

\section{Email address:}

reubenrine@yahoo.com (R. C. Rine)

${ }^{*}$ Corresponding author

\section{To cite this article:}

Reuben Christopher Rine, Gyar Silas Dogara, Mwanta Dachung Pam. Knowledge, Attitude and Practice of Rabies in and Around Lafia Metropolis, Nigeria. Central African Journal of Public Health. Vol. 3, No. 3, 2017, pp. 27-33. doi: 10.11648/j.cajph.20170303.11

Received: June 6, 2017; Accepted: June 27, 2017; Published: July 25, 2017

\begin{abstract}
Rabies is endemic in Nigeria and other developing countries, killing 55,000 people annually. This descriptive cross-sectional study assessed the knowledge, attitudes and practices of rabies in and around Lafia, Central Nigeria. Semistructured questionnaires were administered to 200 consenting respondents from urban and sub-urban areas in Lafia. Of the 200 respondents, $76.5 \%$ heard of rabies with $89 \%$ and $64 \%$ from urban and sub-urban areas. There was no significant difference on the awareness of rabies among respondents from urban and sub-urban areas $(\mathrm{P}>0.05)$. Although there was misperception about the cause of rabies, $41 \%$ of the respondents indicated that it can be transmitted through dog bite and contact with open wound, as $36.5 \%$ were aware that human and other domestic animals can be affected by rabies. Sudden change in behavior was the obvious clinical manifestation after dog bite as asserted by $42.5 \%$ of the respondents. Majority $(54.0 \%)$ of the respondents will seek post-exposure prophylaxis after dog bite, $18.5 \%$ will seek traditional treatment, $16.5 \%$ both the later and the former while $11.0 \%$ will not take any measure. However, $77.5 \%$ of the respondents indicated that legs were the commonest place of dog bite, $69.5 \%$ mentioned children as the most risky population. Only $14.0 \%$ and $18.5 \%$ of the respondents vaccinated their dog and were also vaccinated against rabies while $25.5 \%$ and $22.5 \%$ recorded the availability of both vaccines. After dog bite, $53.5 \%$ and $37.5 \%$ of the respondents will prefer to tie and kill the dogs, as $9.0 \%$ will take no action. Therefore, the need for rabies awareness programmes within the study area is vital. Rabies vaccines, immunoglobulin and facilities that administer them must become affordable and readily available locally for both dogs and humans.
\end{abstract}

Keywords: Attitude, Knowledge, Practice, Rabies, Vaccines

\section{Introduction}

Rabies is one of the oldest recognized infectious diseases which affects all mammals (Rupprecht et al., 2002). The disease is caused by a rhabdovirus (Warrell and Warrell, 2004, Hankins and Rosekrans, 2004) and is transmitted to humans by animal bites, most usually domestic dogs (WHO, 1999). It is estimated that over 10 million people are exposed to rabies annually (Knobel et al., 2005), with almost 100\% case fatality rate (Ameh et al., 2014). The disease remains a major socio-economic and public health problem in developing countries, claiming the lives of an estimated 55,000 people each year (Coleman et al., 2004; Knobel et al., 2005).

The disease is endemic in developing countries including
Nigeria and other parts of sub-Saharan Africa and Asia (Harry et al., 1984; WHO, 2005) with heavy losses in human and livestock population and is often misdiagnosed, underdiagnosed and underreported (Adedeji et al., 2010; Ehizibolo et al., 2011). About $98 \%$ of human rabies deaths have been documented to have been caused by almost and always bite of a rabid dog (Ruppretch, 2008). The annual cost of rabies in Africa and Asia was estimated at US\$ 583.5 million, most of which is due to the cost of post exposure prophylaxis (PEP) (Knobel et al., 2005).

Although rabies has the highest case fatality rate of any disease known to man, the disease is preventable (Ertl, 2009, Lembo et al., 2011). The high burden of rabies mortality in most developing countries suggests that, despite the existence of effective human and animal rabies vaccines, rabies 
prevention and control efforts in these settings are inadequate (Sambo et al., 2014). In Nigeria, it has not been possible to successfully control rabies, instead evidences show that the disease is on the increase (Ogunkoya, 1997).

Knowledge, attitudes and practices (KAP) studies have been widely used around the world for different applications in public health, based on the principle that increasing knowledge will result in changing attitudes and practices to minimize disease burden (Mascie-Taylor et al., 2003). KAP surveys provide a suitable format to evaluate existing programmes and to identify effective strategies for behavior change (Koenraadt et al., 2006). Many published studies demonstrate the influence of increasing community knowledge on the control and prevention of infectious diseases. The motivation behind this study was the need to provide baseline data that would allow the identification of knowledge gaps that may be affecting rabies control and prevention practices in study area.

Little or no information is available on the epidemiology of rabies in Lafia, Central Nigeria. The obvious presence of high population of dogs with poor management contributes to high endemicity of rabies in the study area. More so, dog meat is readily consumed and many dog meat processors and dog owners may not know about the devastating effects of rabies in humans and the potential risk of handling dogs. Thus, they may engage in some practices that may therefore expose them to the disease. This study was carried out to assess the knowledge, attitudes and practices (KAP) about rabies and associated factors among residents in Lafia, Central Nigeria.

\section{Materials and Methods}

\subsection{Study Area and Population}

The study was carried out in Lafia, the capital of Nasarawa State, located in Northcentral geopolitical zone of Nigeria. Lafia is densely populated with 330,712 inhabitants (Census, 2006). It is located on latitude $8^{\circ} 28^{\prime} \mathrm{N}$ and longitude $8^{\circ} 31^{\prime} \mathrm{E}$ (Hogben et al., 2013), a sizable area characterized by poor drainage and sanitation with garbage dumps in close proximity to residential buildings. Hausa and English languages are most commonly spoken by all residents.

\subsection{Study Design and Population}

A community based cross sectional study was used to assess the knowledge, attitudes and practices of the community on rabies using semi structured questionnaire between January to October, 2015. The study populations were residents of Lafia metropolis and its surrounding.

\subsection{Ethical Consideration}

Informed consent was obtained from the respondents. They were made to understand that participation is voluntary and there was no consequence for non-participation. All information obtained was kept confidential.

\subsection{Sampling and Survey Method}

Two hundred (200) respondents were selected for this study using convenience sampling. Self-administered semistructured questionnaires were used for data collection from consenting respondents. The questionnaires captured information on sociodemographic variables, knowledge, attitudes and practices regarding rabies.

\section{Data Analysis}

Information collected from the respondents were entered and analyzed with Statistical Package for Social Sciences version (SPSS) 15 software. Descriptive statistics were done and frequencies and proportions were used to summarize variables of interest.

\section{Results}

Table 1 shows the profiles of the respondents from the urban (100) and sub-urban (100) areas. Among the 200 respondents, 105 were male and 95 were females. Majority of the respondents' age groups included in the range of 21 25 and $16-20$ years and $42.5 \%$ of the respondents have attended higher education. Most of the respondents are singles $(64.5 \%)$, Christians $(66.5 \%)$ and are involved in other forms of occupation ( $56 \%$ ).

Table 2 shows the Knowledge of the respondents on rabies. About 1153 (76.5\%) of the respondents were aware of the disease. Majority of the respondents 95 (47.5\%) and $73(36.5 \%)$ described virus as the cause of the disease and humans and other domestic animals as the species affected by rabies while $96(48.0 \%)$ indicated that dog bite only is the mode of transmitting rabies. Among the 200 respondents, $85(42.5 \%)$ asserted that sudden change in behaviour was the obvious clinical manifestation of rabies while $103(51.5 \%)$ were aware that rabies can be preventable by vaccine. With regards to previous training/orientation on rabies, 31 (15.5\%) had such training while 169 (84.5\%) had none.

As indicated in table 3, $67(33.5 \%)$ and $28(14 \%)$ of the respondents indicated that they keep and vaccinated their $\operatorname{dog}(\mathrm{s})$, as only $51(25.5 \%)$ reported the availability of $\operatorname{dog}$ vaccines. While 97 (48.5) kept their dog indoor, 103 (51.5\%) left their dogs to move freely. Majority $163(81.5 \%)$ of the respondents were never vaccinated against rabies, as only 45 $(22.5 \%)$ reported the availability of human rabies vaccines. Children were the most vulnerable group at risk of the disease as reported by $139(69.5 \%)$ while $155(77.5 \%)$ indicated that leg is the frequent place of bite by dog. With regards to the action taken after been bitten by dog, 108 $(54.0 \%)$ and $37(18.5 \%)$ of the respondents will seek postexposure vaccine and traditional treatment respectively while $33(16.5 \%)$ will seek for both. Actions taken against the biting dog were to tie and kill them as indicated by 101 $(53.5 \%)$ and $75(37.5 \%)$ respondents while $24(9.0 \%)$ respondents will do nothing. 
Table 1. Sociodemographic Characteristics of Respondents.

\begin{tabular}{|c|c|c|c|}
\hline \multicolumn{4}{|c|}{ Number and Percentage of Respondents } \\
\hline Characteristic of Respondents & Total $(\%) n=200$ & Urban (\%) n = 97 & Sub-urban (\%) n = 103 \\
\hline \multicolumn{4}{|l|}{ Sex } \\
\hline Male & $105(52.5 \%)$ & $52(53.6 \%)$ & $53(51.5 \%)$ \\
\hline Female & $95(47.5 \%)$ & $45(46.4 \%)$ & $50(48.5 \%)$ \\
\hline \multicolumn{4}{|l|}{ Age group } \\
\hline$<15$ & $20(10 \%)$ & $18(318.6 \%)$ & $2(1.9 \%)$ \\
\hline $16-20$ & $46(23 \%)$ & $24(24.7 \%)$ & $22(21.4 \%)$ \\
\hline $21-25$ & $60(30 \%)$ & $25(25.8 \%)$ & $35(33.9 \%)$ \\
\hline $26-30$ & $44(22 \%)$ & $18(18.6 \%)$ & $26(25.2 \%)$ \\
\hline $31>$ & $30(15 \%)$ & $12(12.4 \%)$ & $18(17.5 \%)$ \\
\hline \multicolumn{4}{|l|}{ Level of Education } \\
\hline Cannot read and write & $11(5.5 \%)$ & $3(3.1 \%)$ & $7(6.8 \%)$ \\
\hline Informal (read and write only) & $28(14 \%)$ & $15(15.5 \%)$ & $11(10.7 \%)$ \\
\hline Primary school & $23(11.5 \%)$ & $16(16.5 \%)$ & $7(6.8 \%)$ \\
\hline Secondary school & $53(26.5 \%)$ & $24(24.7 \%)$ & $29(28.2 \%)$ \\
\hline Higher education & $85(42.5 \%)$ & $39(40.2 \%)$ & $49(47.6 \%)$ \\
\hline \multicolumn{4}{|l|}{ Occupation } \\
\hline Health professional & $5(2.5 \%)$ & $1(1.0 \%)$ & $4(3.9 \%)$ \\
\hline Veterinarian & $4(2.0 \%)$ & $1(1.0 \%)$ & $3(2.9 \%)$ \\
\hline Farmer & $14(7.0 \%)$ & $6(6.2 \%)$ & $8(7.8 \%)$ \\
\hline Jobless & $22(11.0 \%)$ & $16(16.5 \%)$ & $6(5.8 \%)$ \\
\hline Others & $155(56.0 \%)$ & $73(75.3 \%)$ & $82(79.6 \%)$ \\
\hline \multicolumn{4}{|l|}{ Marital status } \\
\hline Single & $129(64.5 \%)$ & $68(70.1 \%)$ & $61(59.2 \%)$ \\
\hline Married & $62(31 \%)$ & $23(23.7 \%)$ & $39(37.9 \%)$ \\
\hline Divorced & $9(4.5 \%)$ & $6(6.2 \%)$ & $3(2.9 \%)$ \\
\hline \multicolumn{4}{|l|}{ Religion } \\
\hline Christian & $133(66.5 \%)$ & $81(83.5 \%)$ & $52(50.5 \%)$ \\
\hline Muslim & $52(26 \%)$ & $8(8.3 \%)$ & $44(42.7 \%)$ \\
\hline Pagan & $10(5 \%)$ & $5(5.2 \%)$ & $5(4.9 \%)$ \\
\hline Others & $5(2.5 \%)$ & $3(3.1 \%)$ & $2(1.9 \%)$ \\
\hline
\end{tabular}

Table 2. Knowledge of the Respondents on Rabies.

\begin{tabular}{|c|c|c|c|}
\hline \multirow[b]{2}{*}{ Parameter } & \multicolumn{3}{|c|}{ Number and Percentage of Respondents } \\
\hline & Total $(\%) n=200$ & Urban $(\%) n=100$ & Sub-urban $(\%) n=100$ \\
\hline \multicolumn{4}{|l|}{ Awareness of Rabies } \\
\hline Yes & $153(76.5 \%)$ & $89(89.0 \%)$ & $64(64.0 \%)$ \\
\hline No & $47(23.5 \%)$ & $11(11.0 \%)$ & $36(36.0 \%)$ \\
\hline \multicolumn{4}{|l|}{ Cause of Rabies } \\
\hline Virus & $95(47.5 \%)$ & $65(65.0 \%)$ & $30(30.0 \%)$ \\
\hline Bacterium & $23(11.5 \%)$ & $13(13.0 \%)$ & $10(10.0 \%)$ \\
\hline Starvation and thirst & $20(10.0 \%)$ & $10(10.0 \%)$ & $10(10.0 \%)$ \\
\hline I don't know & $62(31.0 \%)$ & $12(12.0 \%)$ & $50(50.0 \%)$ \\
\hline \multicolumn{4}{|l|}{ Species affected by Rabies } \\
\hline Dogs only & $62(31.0 \%)$ & $34(34.0 \%)$ & $28(28.0 \%)$ \\
\hline Human only & $22(11.0 \%)$ & $05(05.0 \%)$ & $17(17.0 \%)$ \\
\hline Dog and human & $43(21.5 \%)$ & $22(22.0 \%)$ & $21(21.0 \%)$ \\
\hline Human and other domestic animals & $73(36.5 \%)$ & $39(39.0 \%)$ & $34(34.0 \%)$ \\
\hline \multicolumn{4}{|l|}{ Means of transmission } \\
\hline Bite only & $74(37.0 \%)$ & $22(22.0 \%)$ & $52(52.0 \%)$ \\
\hline Contact with saliva only & $19(9.5 \%)$ & $18(18.0 \%)$ & $01(01.0 \%)$ \\
\hline Bite and contact with open wounds & $82(41.0 \%)$ & $49(49.0 \%)$ & $33(33.0 \%)$ \\
\hline Infected meat and others & $25(12.5 \%)$ & $11(11.0 \%)$ & $14(14.0 \%)$ \\
\hline \multicolumn{4}{|c|}{ Animal species that transmit Rabies virus to human } \\
\hline Dog only & $96(48.0 \%)$ & $42(42.0 \%)$ & $54(54.0 \%)$ \\
\hline Dog and cat only & $22(11.0 \%)$ & $05(05.0 \%)$ & $17(17.0 \%)$ \\
\hline Bat, dog and cat & $55(27.5 \%)$ & $44(44.0 \%)$ & $11(11.0 \%)$ \\
\hline Other domestic animals & $27(13.5 \%)$ & $09(09.0 \%)$ & $18(18.0 \%)$ \\
\hline \multicolumn{4}{|l|}{ Signs and symptoms } \\
\hline Salivation only & $34(17.0 \%)$ & $23(23.0 \%)$ & $11(11.0 \%)$ \\
\hline Sudden change in behavior & $85(42.5 \%)$ & $36(36.0 \%)$ & $49(49.0 \%)$ \\
\hline Pain at bite site & $57(28.5 \%)$ & $27(27.0 \%)$ & $30(30.0 \%)$ \\
\hline Loss of appetite only & $24(12.0 \%)$ & $14(14.0 \%)$ & $10(10.0 \%)$ \\
\hline Knows that rabies could be prevente & & & \\
\hline
\end{tabular}




\begin{tabular}{llll}
\hline & \multicolumn{3}{l}{ Number and Percentage of Respondents } \\
\hline Parameter & Total $(\mathbf{\%}) \mathbf{n}=\mathbf{2 0 0}$ & Urban $(\mathbf{\%}) \mathbf{n}=\mathbf{1 0 0}$ & Sub-urban $(\mathbf{\%}) \mathbf{n}=\mathbf{1 0 0}$ \\
\hline Yes & $103(51.5 \%)$ & $79(79.0 \%)$ & $24(24.0 \%)$ \\
No & $97(48.5 \%)$ & $21(21.0 \%)$ & $76(76.0 \%)$ \\
Receives information about rabies prevention and vaccination from & & & \\
Health worker & $41(20.5 \%)$ & $23(23.0 \%)$ & $18(18.0 \%)$ \\
Television & $19(9.5 \%)$ & $14(11.0 \%)$ & $05(05.0 \%)$ \\
Radio & $11(5.5)$ & $06(06.0)$ & $05(05.0)$ \\
Livestock officers & $56(28.0)$ & $28(28.0)$ & $28(28.0)$ \\
Others & $73(36.5)$ & $29(29.0)$ & $44(44.0)$ \\
Knows that rabies vaccine could be obtain from & & & \\
PHC/ General Hospital & $05(2.5 \%)$ & $02(02.0 \%)$ & $03(03.0 \%)$ \\
Private hospitals/Pharmacy & $18(09.0 \%)$ & $11(11.0 \%)$ & $07(07.0 \%)$ \\
Teaching/Specialist Hospitals & $65(32.5)$ & $39(39.0)$ & $26(26.0)$ \\
Research institutes & $50(25.0)$ & $31(31.0)$ & $19(19.0)$ \\
Livestock Departments & $62(31.0)$ & $25(25.0)$ & $37(37.0)$ \\
Training/Orientation on Rabies & & \\
Yes & $31(15.5 \%)$ & $26(26.0 \%)$ & $05(9.0 \%)$ \\
No & $169(84.5 \%)$ & $74(74.0 \%)$ & $95(91.0 \%)$ \\
\hline
\end{tabular}

Table 3. Attitudes and Practices of Respondents.

\begin{tabular}{|c|c|c|c|}
\hline \multirow[b]{2}{*}{ Parameter } & \multicolumn{3}{|c|}{ Number and Percentage of Respondents } \\
\hline & Total $(\%) \mathbf{n}=\mathbf{2 0 0}$ & Urban $(\%) n=100$ & Sub-urban $(\%) n=100$ \\
\hline \multicolumn{4}{|l|}{ Action against biting dog } \\
\hline Tie them & $101(53.5 \%)$ & $53(53.0 \%)$ & $48(48.0 \%)$ \\
\hline Kill them & $75(37.5 \%)$ & $34(34.0 \%)$ & $41(41.0 \%)$ \\
\hline Do nothing & $24(9.0 \%)$ & $13(13.0 \%)$ & $11(11.0 \%)$ \\
\hline \multicolumn{4}{|l|}{ Action for bitten man } \\
\hline Post-exposure vaccine & $108(54.0 \%)$ & $64(50.5 \%)$ & $44(57.3 \%)$ \\
\hline Traditional treatment & $37(18.5 \%)$ & $16(22.7 \%)$ & $21(14.6 \%)$ \\
\hline Both & $33(16.5 \%)$ & $13(13.4 \%)$ & $20(19.4 \%)$ \\
\hline None of the above & $22(11.0 \%)$ & $07(13.4 \%)$ & $15(8.7 \%)$ \\
\hline \multicolumn{4}{|l|}{ Action for bitten animal } \\
\hline Kill them & $80(40.0 \%)$ & $37(37.0 \%)$ & $43(43.0 \%)$ \\
\hline Tie them & $31(15.5 \%)$ & $21(21.0 \%)$ & $10(10.0 \%)$ \\
\hline No action taken & $89(44.5 \%)$ & $42(42.0 \%)$ & $47(47.0 \%)$ \\
\hline \multicolumn{4}{|l|}{ Do you keep dogs? } \\
\hline Yes & $67(33.5 \%)$ & $41(41.0 \%)$ & $26(26.0 \%)$ \\
\hline No & $133(66.5 \%)$ & $59(59.0 \%)$ & $74(74.0 \%)$ \\
\hline \multicolumn{4}{|c|}{ Do you vaccinate your dogs? } \\
\hline Yes & $28(14.0 \%)$ & $17(17.0 \%)$ & $11(11.0 \%)$ \\
\hline No & $39(19.5 \%)$ & $24(24.0 \%)$ & $15(15.0 \%)$ \\
\hline No answer & $133(66.5 \%)$ & $59(59.0 \%)$ & $74(74.0 \%)$ \\
\hline \multicolumn{4}{|c|}{ Availability of vaccine for dog } \\
\hline Yes always & $51(25.5)$ & $41(41.0)$ & $10(10.0)$ \\
\hline Sometimes & $85(42.5)$ & $42(42.0)$ & $43(43.0)$ \\
\hline Not available & $64(32.0)$ & $17(17.0)$ & $47(47.0)$ \\
\hline \multicolumn{4}{|c|}{ Have you ever been vaccinated against rabies } \\
\hline Yes & $37(18.5)$ & $22(15.46)$ & $15(21.4)$ \\
\hline No & $163(81.5)$ & $78(84.54)$ & $85(78.64)$ \\
\hline \multicolumn{4}{|c|}{ Availability of vaccine for human } \\
\hline Yes always & $45(22.5)$ & $32(32.0)$ & $13(13.0)$ \\
\hline Sometimes & $100(50)$ & $57(57.0)$ & $43(43.0)$ \\
\hline Not available & $55(27.5)$ & $11(11.0)$ & $44(44.0)$ \\
\hline \multicolumn{4}{|l|}{ Most risky population } \\
\hline Children & $139(69.5)$ & $66(66.0)$ & $73(73.0)$ \\
\hline Young people & $33(16.5)$ & $15(15.0)$ & $18(18.0)$ \\
\hline Older people & $28(14.0)$ & $19(19.0)$ & $09(09.0)$ \\
\hline \multicolumn{4}{|c|}{ Dog management practices } \\
\hline Left free & $103(51.5)$ & $42(42.0)$ & $61(61.0)$ \\
\hline Kept indoor & $97(48.5)$ & $58(58.0)$ & $39(39)$ \\
\hline \multicolumn{4}{|c|}{ Is there specialized hospital for rabies } \\
\hline Yes & $20(10.0)$ & $14(14.0)$ & $6(6.0)$ \\
\hline No & $180(90.0)$ & $83(83.0)$ & $97(97.0)$ \\
\hline \multicolumn{4}{|l|}{ Frequent place of bite } \\
\hline Leg & $155(77.5)$ & $69(69.0)$ & $86(86.0)$ \\
\hline Head & $15(7.5)$ & $9(9.0)$ & $6(6.0)$ \\
\hline
\end{tabular}




\begin{tabular}{|c|c|c|c|}
\hline \multirow[b]{2}{*}{ Parameter } & \multicolumn{3}{|c|}{ Number and Percentage of Respondents } \\
\hline & Total $(\%) \mathbf{n}=\mathbf{2 0 0}$ & Urban $(\%) n=100$ & Sub-urban (\%) n = 100 \\
\hline Hand & $12(6.0)$ & $7(7.0)$ & $5(5.0)$ \\
\hline Body & $18(9.0)$ & $12(12.0)$ & $6(6.0)$ \\
\hline
\end{tabular}

\section{Discussion}

The results of our findings indicate that $76.5 \%$ of the respondents have heard about rabies from different sources, with $89.0 \%$ and $64.0 \%$ from urban and sub-urban areas respectively. The level of awareness obtained from this study is in consonance with the findings of Ichhupujani et al. (2006), Matibag et al. (2007), Ali et al. (2013) and Sumon et al. (2016) who obtained $68.7 \%, 78.7 \%, 75.2 \%$ and $73.0 \%$ from India, Sri Lanka, Ethiopia and Bangladesh. However, higher proportions of $96.0 \%, 96.4 \%, 99.0 \%$ and $99.0 \%$ were reported by Sambo et al. 2014, (in Tanzania), Shumuye et al., 2014 (in Ethiopia), Tadesse et al. 2014, (in Ethiopia) and Moran et al. 2015, (in Guatemala). The high level of awareness of rabies among the participants as recorded in this study may be due to the endemicity of rabies and frequent reports of rabies incidence in and around Lafia, and the availability of information from various sources. Respondents from the urban area were more aware $(89.0 \%)$ of rabies than those from the sub-urban (64.0\%). This may be attributed to the easy and constant access to health information by the urban dwellers from different sources. More so, they are more enlightened and have direct access to health care facilities. The current results also indicated that the respondents were informed about rabies from health workers, television, radio and livestock officers which suggests that the mass media and health/livestock workers could work harder to disseminate rabies relevant information.

Only $47.5 \%$ of the respondents knew the actual cause of rabies. Other respondents believed that the disease in dogs is caused by bacteria, starvation and thirst while others don't know. In a study in Ethiopia, only $18 \%$ of the respondents knew that rabies is caused by virus (Shumuye et al., 2014). This could be due to the difference in community awareness in the study areas. This misunderstanding could probably be explained by the opinion of asymptomatic rabies carrier dogs in which stressors like starvation and thirst might induce the development of clinical rabies in these carrier dogs. But the idea of asymptomatic rabies carrier dogs by itself is a controversial issue (Wilde et al., 2009), and the association of stressors to the development of clinical rabies might be an implausible claim. About $48.0 \%$ of the respondents reported that dogs most frequently transmit the infection to humans. Very few respondents knew that rabies could be transmitted by species other than domestic dogs. This is consistent with findings from a survey in Thailand which found that only $16 \%$ of participants knew that all mammals can suffer from rabies (Kongkaew et al., 2004). Furthermore, domestic dogs have been reservoir of rabies and a source of rabies infection to humans and other animals (John, 2005; Joo et al., 2011). In many parts of the world, especially Africa and Asia, 85-
$90 \%$ of human rabies cases were been caused by dog bite (Tang et al., 2005; Fitzpatrick et al., 2012).

Majority (51.5\%) of the respondents believed that rabies could be prevented by vaccine. This is in agreement with the finding of Lai et al. 2005, which reported that $49.2 \%$ respondents held true the prevention of rabies by vaccine. Mass dog vaccination is the most effective measure to control rabies and prevent human deaths (Bogel, 1987). While the majority of respondents knew of the need for dog vaccination, and were willing to vaccinate their dogs, only $14.0 \%$ reported to have previously vaccinated their dogs, which reflects a lack of rabies control programmes. Indeed, most respondents reported that dog vaccines in the study area are not regularly available. Lower rate of dog vaccination was also recorded by Abraham et al. 2013, and Lai et al. 2005. It is commonly perceived that many African communities are characterised by low levels of responsible dog ownership. Indeed, in this study $51.5 \%$ respondents left their dogs to move freely without restrain. This indicates the presence of high risk of rabies. The practice of allowing dogs to roam freely would facilitate the spread of rabies in the animal population and would make rabies a continuing zoonotic threat to humans. Also, only $18.5 \%$ of respondents were once vaccinated against rabies, as $50.0 \%$ and $27.5 \%$ reported that the vaccines are seldom and never available. This shows that vast majority of individuals in the study area are at risk of rabies when bitten by rabid animal.

Most of the respondents (69.5\%) reported that children are the most risky population to the disease. Other studies have found that children and young people were the most vulnerable group for animal bites (Knobel et al., 2005; Sriaroon et al., 2006; Dodet et al., 2008; Shumuye et al., 2014). The reason for this vulnerability is likely their countenance of natural affection for animals, particularly cats and dogs. Sometimes bites may take place with provocation from children like stone throwing, beating, chasing or running at the sight of the dogs. In addition, Assefa et al. (2010) has reported that elders are well aware of the danger of rabies and look for medical care than children.

Although more than half of the respondents $(54.0 \%)$ will go for post exposure prophylaxis after being bitten by dogs, $18.5 \%$ will prefer the traditional treatment while $16.5 \%$ will do both the later and the former. These results are consistent with studies in other countries where people would seek traditional practices instead of modern post-exposure prophylaxis treatment (Sekhon et al., 2002; Sudarshan et al., 2007; Rumana et al., 2013). These types of treatment seeking behaviour may be the outcome of persisting many myths and false beliefs among the respondents associated with dog bite management and a lack of education regarding effective prevention of rabies. Furthermore, socioeconomic conditions (low level of education, financial constraints), insufficient 
vaccine and immunoglobulin supply to the government hospitals, distance from the dog bite victims place of residence to the government hospitals may be responsible for the low vaccine coverage among dog bite victims in the study area. The World Health Organization (WHO) recommends wound washing and vaccination immediately after contact with a suspect rabid animal which can prevent almost 100\% of rabies deaths (WHO, 2015).

Findings from this study revealed that most of the respondents $(77.5 \%)$ recorded that leg is the frequent place of bite by dogs. Defensive aggression is likely a major contributing factor to dog bites. Bites to the legs and feet of humans may be correlated to territory protection by dogs (Isek, 2013). The occurrence of dog bites mostly on the legs may be due to proximity of this part of the body to the animal. Also, it is likely that victims would have used legs in an attempt to separate fighting dogs or defending themselves against dog attacks resulting in more bites on the lower extremities.

In this study, we found that the attitudes of the respondents towards biting dog were negative. Most of the respondents preferred to tie and kill the dog so as to prevent such attacks to others. It is definitely not a good practice as many dogs may not be suffering from rabies. Similar practice was also reported by Dhaliwal et al. 2000. A study in India also reported that $43 \%$ of the respondents felt that killing excess and suspected aggressive dogs is the best method for controlling rabies within the stray dog population (Herbert et al., 2012). Furthermore, $84.5 \%$ of the respondents had no previous training/orientation on rabies. This illustrates that training on rabies related aspects has not been given at community level. Therefore, public extensive education about rabies should be given to community to increase their awareness. Raising community awareness level has been mentioned as important tool to control rabies by many scholars (Eshetu at al., 2002; Wudu et al., 2013). But building awareness is generally thought to be the first step to control rabies. To enhance rabies awareness, first of all, it is necessary to use information and education campaigns throughout the country and school-based rabies control programmes should be implemented thereafter. Veterinarians and physicians can play a crucial role in controlling rabies through a one-health approach by linking animal and human health (Sumon et al., 2016). Also, participatory epidemiology approach can be used for community involvement in rabies control and prevention.

\section{Conclusion}

Although respondents showed high level of knowledge and awareness regarding rabies in the study area, there are some KAP gaps regarding the cause of rabies, animals affected, modes of transmission, actions taken after suspected animal bite, poor treatment seeking behaviour, and inability to access community health facilities for rabies treatment and/or prophylaxis. This indicates the existence of high risk of the disease which poses a health hazard and makes difficult the control of rabies in the study area. Therefore, the need for rabies awareness programmes within the community is vital. Rabies vaccines, immunoglobulin and facilities that administer them must become affordable and readily available locally for both dogs and humans. Awareness about rabies can be increased by undertaking targeted awareness campaigns using the mass media. This is achievable by initiatives both by the government and non-government organisations.

\section{References}

[1] Abraham, A., Eshetu, Y. and Desalegn, S. (2013). A study on knowlwdge, attitude and practice of rabies among residents of addis ababa, Ethiopia. Ethiopia Veterinary Journal, 17 (2): 1925 .

[2] Adedeji, A. O., Eyarefe, O. D., Okonko, I. O., Ojezele, M. O., Amusan, T. A., and Abubakar, M. J. (2010). Why is there still rabies in Nigeria? A review of the current and future trends in the epidemiology, prevention, treatment, control and possible eradication of rabies. British Journal of Dairy Sciences, 1 (1): 10-25.

[3] Ali, A., Eshetu, Y. A. and Desalegn, S. (2013). A Study on Knowledge, Attitude and Practice of rabies among residents in Addis Ababa, Ethiopia. Ethiopia Veterinary Journal, 17 (2): 19-35.

[4] Ameh, V. O., Dzikwi A. A. and Umoh, J. U. (2014). Assessment of Knowledge, Attitude and Practice of Dog Owners to Canine Rabies in Wukari Metropolis, Taraba State Nigeria. Global Journal of Health Science, 6 (5): 226-240.

[5] Assefa, D., Abrham, A., Mekoro, B., Bethelehem, N., Eshtu, Y. and Kedir, H. (2010). The status of rabies in ethiopia: a retrospective record review. Ethiopia Journal of Health Development, 24 (2): 127-132.

[6] Bogel, K. (1987). Guidelines for Dog Rabies Control. Geneva, Switzerland: WHO.

[7] Coleman, P. G., Fevre, E. M. and Cleaveland, S. (2004). Estimating the public health impact of rabies. Emerging Infectious Diseases, 10: 140-142.

[8] Dhaliwal, D. S. and Ravneet, S. D. (2000). An Analysis of 51 Cases of Hydrophobia at Amritsar (Punjab). Indian Journal of Community Medicine, 25 (3): 118-120.

[9] Dodet, B., Goswami, A., Gunasekera, A., de Guzman, F., Jamali, S. and Montalban, C. (2008). Rabies awareness in eight Asian countries. Vaccine, 26: 6344-6348.

[10] Ehizibolo, D. O., Ehizibolo, P. O., Ehizibolo, E. E., Sugun, M. Y., and Idachaba, S. E. (2011). The control of neglected zoonotic diseases in Nigeria through animal intervention: an overview. African Journal of Biomedical Research, 14 (2): 81-88.

[11] Ertl, H. C. J. (2009). Novel Vaccines to Human Rabies. Plos Neglected Tropical Diseases, 3: e515.

[12] Fitzpatrick, M., Hampson, K., Cleaveland, S., Meyers, L., Townsend, J. and Galvani, A. (2012). Potential for rabies control through dog vaccination in wildlife abundant community of Tanzania. Neglected Tropical Diseases, 6: 1796. 
[13] Hankins, D. G. and Rosekrans, J. A. (2004). Overview, prevention, and treatment of rabies. Mayo Clin Proc, 79: 671-6.

[14] Harry, T. O., Adeiga, A., Anyiwo, C. E., and Nasid, A. (1984). Anti-rabies treatment of dog bite Victims in Lagos, Nigeria: Trial of Suckling Mouse Brain and Fetal Bovine Kidney cell rabies Vaccinee. Vaccine, 2 (4): 257-260. http://dx.doi.org/10.1016/0264-410X(84)90040-9

[15] Herbert, M., Basha, R. and Thangaraj, S. (2012). Community perception regarding rabies prevention and stray dog control in urban slums in India. Journal of Infection and Public Health, 5: 374-380.

[16] Ichhupujani, R. M., Chhabra, V., Bhattacharya, M. D., Lal, S. (2006). Knowlwdge attitudes and practices about animal bites and rabies in general community-a multi-centric study. Journal of communicable Diseases, 38 (40): 355-361.

[17] John, B. (2005). Canine rabies ecology in southern Africa. Journal of Emerging Infectious Diseases, 11: 1337-1142.

[18] Joo, Y., Lee, J., Lee, K., Bang, H. and Lee, W. (2012). Retrospective study of extensive vaccination programmes for canine rabies control and public health in korea. Journal of Infectious Diseases, 64: 513-515.

[19] Knobel, D. L., Cleaveland, S., Coleman, P. G., Fevre, E. M., Meltzer, M. I., Miranda, M. E. G., Shaw, A., Zinsstag, J. and Meslin, F. X. (2005). Reevaluating the burden of rabies in Africa and Asia. Bulletin of the World Health Organization, 83: 360-368.

[20] Kongkaew, W., Coleman, P., Pfeiffer, D. U., Antarasena, C. and Thiptara, A. (2004). Vaccination coverage and epidemiological parameters of the owned-dog population in Thungsong District, Thailand. Preview in Veterinary Medicine, 65: 105-115.

[21] Lembo, T., Attlan, M., Bourhy, H., Cleaveland, S., Costa, P., De Balogh, K., Dodet, B., Fooks, A. R., Hiby, E., Leanes, F., Meslin, F. X., Miranda, M. E., Muller, T., Nel, L. H., Rupprecht, C. E., Tordo, N., Tumpey, A., Wandeler, A. and Briggs, D. J. (2011). Renewed global partnerships and redesigned roadmaps for rabies prevention and control. Veterinary Medicine International, 9 (2): 31-49.

[22] Mascie-Taylor, C. G. N., Karim, R., Karim, E., Akhtar, S. and Ahmed, T. (2003). The cost-effectiveness of health education in improving knowledge and awareness about intestinal parasites in rural Bangladesh. Econ Hum Biol., 1: 321-330.

[23] Matibag, G. C., Taro, K., Pallegoda, V. R. K., Thula, G. W., Anil, W. K., Anuruddhika, D., Niranjala, D., Panduka, D. G., Yoshihide, O., Koji, K. and Hiko, T. (2007). Knowledge, Attitudes, and Practices Survey of Rabies in a Community in Sri Lanka. Environmental Health and Preventive Medicine, 12: 84-89.

[24] Moran, D., Juliao, P., Danilo, A., Kim, A. L., James, A. E., Amy, T. G., Brett, P., Charles, R. and Sergio, R. (2015). Knowledge, attitudes and practices regarding rabies and exposure to bats in two rural communities in Guatemala. $B M C$ Research Notes, 8: 955.

[25] Ogunkoya, A. B. (1997). Rabies: Basic concepts, problems and prospects of its control in Nigeria. Oreofe Nigeria Limited, 51-69.

[26] Rumana, R., Sayeed, A., Basher, A., Islam, Z., Rahman, M. and Faiz, M. (2013). Perceptions and treatment seeking behavior for dog bites in rural Bangladesh. The Southeast Asian Journal of Tropical Medicine and Public Health, 44: 1-5.

[27] Rupprecht, C. E., Hanlon, C. A. and Hemachudha, T. (2002). Rabies re-examined. The Lancet Infectious Diseases, 2: 327343 .

[28] Ruppretch, C. E. (2008). Current and future trends in the prevention, treatment and control of rabies. Books of proceedings of national conference and workshops on rabies IDR-A. B. U Zaria Nigeria. Pp 253-257.

[29] Sambo, M., Lembo, T., Cleaveland, S., Ferguson, H. M. and Sikana, L. (2014) Knowledge, Attitudes and Practices (KAP) about Rabies Prevention and Control: A Community Survey in Tanzania. PLoS Negl Trop Dis 8 (12): 3310-1317.

[30] Sekhon, A., Singh, A., Kaur, P. and Gupta, S. (2002) Misconceptions and myths in the management of animal bite case. Indian Journal of Community Medicine, 22 (3): 27-31.

[31] Shumuye, G. S., Kassaw, A. T., Haileluel, A. Y. and Sintayehu, M. T. (2014). Study on community knowledge, attitude and practice of rabies in and nearby Gondar town, north west Ethiopia. Journal of Public Health and Epidemiology, 6 (12): 429-43.

[32] Sriaroon, C., Sriaroon, P., Daviratanasilpa, S., Khawplod, P. and Wilde, H. (2006). Retrospective: animal attacks and rabies exposures in Thai children. Travel Medicine and Infectious Disease, 4: 270-274.

[33] Sudarshan, M. K., Madhusudana, S. N., Mahendra, B. J., Rao, N. S., Narayana, D. A. and Rahman, S. A. (2007) Assessing the burden of human rabies in India: results of a national multi-center epidemiological survey. International Journal of Infectious Diseases 11, 29-35.

[34] Sumon, G., Sukanta, C., Najmul, H., Rajub, K. B., Rana, S., Aung, S., Prue, M., Muhammad, B. H., Nitish, C. D. and BeNazir, A. (2016). Awareness of rabies and response to dog bites in a Bangladesh community. Veterinary Medicine and Science, 3: 1-9.

[35] Tadesse, G., Anmaw, S., Mersha, C., Basazinew, B., Tewodros, S. (2014). Assessment of knowledge, attitude and practices about rabies and associated factors: in the case of Bahir Dar town. Global Veterinarian, 13 (3): 348-354.

[36] Tang, X., Lou, M., Zhang, S., Fooks, A., Hu, R. and Tu, C. (2005). Pivotal role of dogs in rabies transmission, china. Journal of Emerging Infectious Diseases, 11: 1970-1972.

[37] Warrell, M. J. and Warrell, D. A. (2004). Rabies and other lyssavirus diseases. Lancet, 363: 959-69.

[38] World Health Organization (1999). World Survey of Rabies No. 34 for the year 1998. WHO document WHO/ CDS/ CSR/ APH/ 99.6. Geneva, Switzerland.

[39] World Health Organization (2005). WHO Technical Report Series, 93 (1), 1-121. WHO Expert Consultation on Rabies, 2004. Geneva: The Organisation First Report.

[40] World Health Organization (2015). Rabies Factsheet. Available at: http://www.who.int/mediacentre/factsheets/fs099/en/ (Accessed 06 January 2016). 